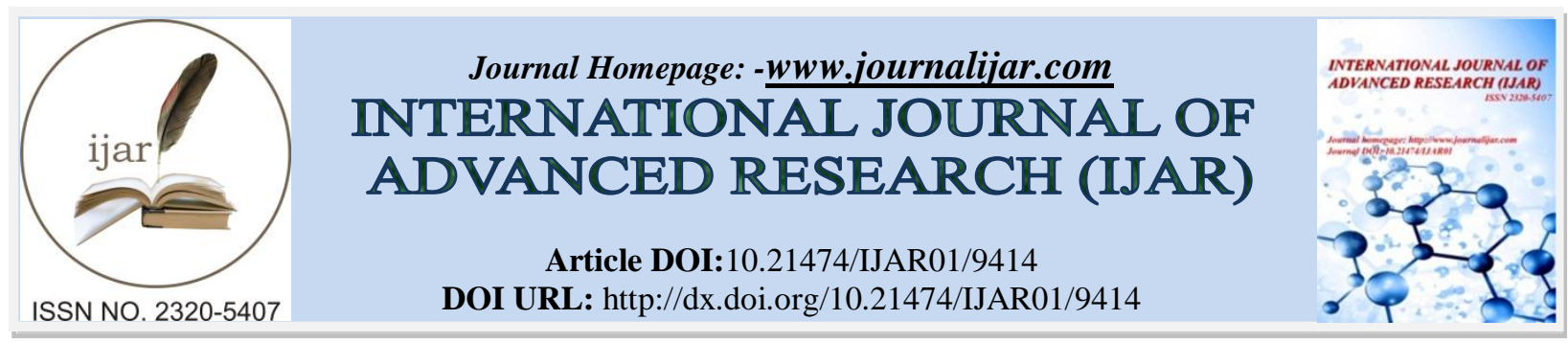

RESEARCH ARTICLE

\title{
TLC AND GC-MS ANALYSIS OF GLORIOSA SUPERBA L.
}

\author{
Dr. K. Geetha. \\ Assistant Professor, Department of Botany, The Standard fireworks Rajaratnam College for Women, Sivakasi.
}

\section{Manuscript Info}

Manuscript History

Received: 20 May 2019

Final Accepted: 22 June 2019

Published: July 2019

Key words:-

Gloriosa superba L. Thin layer chromatography and GC-MS method.

\begin{abstract}
Gloriosa superba L. has been a source of medicine right from ancient time. In the present work, we investigate the acetone extracts of Goriosa superba L. leaves were subjected to thin layer chromatography and GC-MS to know the complexity and diversity of phytoconstituents. The active compounds are separated by thin layer chromatography and GC-MS method using acetone extracts. Thirty bioactive compounds were identified and screened in GC-MS by library search tools. Among the thirty, four compounds were identified as bioactive compounds. Among them a single major peak is observed as butanedioic acid, hydroxyl, also commonly known as malic acid with RT value of 26.96 with peak area of $97.54 \%$.
\end{abstract}

Copy Right, IJAR, 2019,. All rights reserved.

\section{Introduction:-}

Nature has been of material agents for thousands of years and an impressive number of modern drugs have been isolated from natural sources (Cragg and Newman, 2001 and Alam et al., 2009). This has resulted in the use of a large number of medicinal plants with curative properties that can treat various diseases and it is used in ayurvedic, allopathic and homeopathic treatment. According to the World Health Organization, more than $80 \%$ of the world population still relies on herbal medicines as their primary source of heath care. The popularity of using plants for therapeutic purposes has been intensified especially at the onset where traditional health care using traditional medicine is being promoted. Medicinal plants are being used by traditional healers either singly or in combination in the treatment of different types of diseases. Plants used for traditional medicine contain a wide range of substances that can be used to treat chronic as well as infectious diseases. Plants are used medicinally in different countries and are a source of many potent and powerful drugs (Srivastava et al., 1996, Bibitha et al., 2002 and Mahesh and Sathish, 2008). A wide range of medicinal plant parts is used for extract as raw drugs which possess varied medicinal properties and is reported to have minimal side effects (Maghrani et al., 2005). Medicinal plants have been used as sources of medicine in virtually all cultures (Baquar, 1995, Anwannil and Atta, 2006). Traditionally, this treasure of knowledge has been passed on orally from generation to generation without any written document (Samy et al., 2008). The art of use of plants medicine is herbalism (Kavina et al., 2011).

\section{Description Of The Plant}

Gloriosa superba L. (Glory lily) is widely distributed in tropical and sub - tropical parts of India including foothills of Himalayas (Kapoor, 2001). It is a national flower of Zimbabwe and also is a state flower of Tamil Nadu state of India. It is known by different names in India, such as Kalihari, Agnishikha, Languliata and Nangulika. The plant thrives from arid Bundelkhand to the humid Assam valley, India. The generic name Gloriosa means "full of glory"

Corresponding Author:- K. Geetha.

Address:-Assistant Professor of Botany with Specialization in Plant biotechnology,The Standard fireworks Rajaratnam College for Women, Sivakasi. 
and superba means "superb", alluding to the striking red and yellow flowers. Its extreme toxicity requires the most cautious of handling.

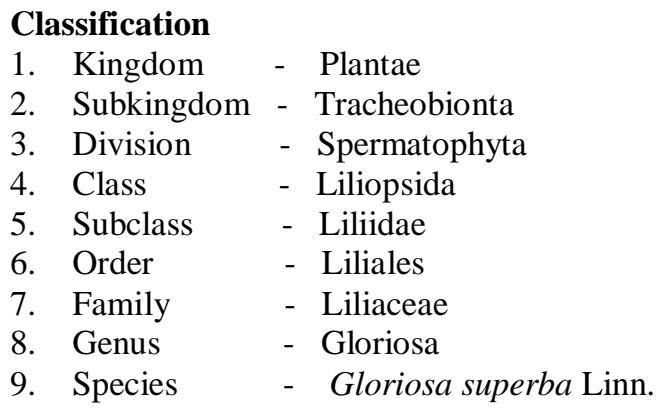

Gloriosa superba $\mathrm{L}$. is an erect, herbaceous, climbing perennial growing between $3.5-6 \mathrm{~m}$ in length, usually trained at $1.5 \mathrm{~m}$ above the ground level. It is adapted to different soil texture and climatic variation. It occurs in thickets, forest edges and boundaries of cultivated areas in warm countries upto height of $253 \mathrm{~cm}$. (Neuwinger, 1994 and Ravindra ade and Mahendra raj, 2009). Flowering is noticed from November to December (Swarnapriya et al., 1995). It is one of the most important medicinal plans of Asia and Africa (Sivakumar et al., 2002, Jana et al., 2011). It has been a well known plant in Indian Ayurveda as well as in pharmacological industries (Asolkar et al., 1992). Almost all parts of it find diverse medicinal usage (Kapoor, 2011). Its rhizomes used as a tonic, anti- periodic, antihelminthic and also against snake bites and scorpion stings.

Gloriosa superba L. is called as 'Mauve beauty', 'Purple prince', 'Modest', 'Orange gem', 'Salman glow' and 'Orange glow' (Bose and Yadav, 1989). It is one of the most important medicinal plants of Asia and Africa (Sivakumar et al., 2002, Jana et al., 2011). It has been a well known plant in Indian Ayurveda as well as in pharmacological industries (Asolkar et al., 1992). Almost all parts of it find diverse medicinal usage (Kapoor, 2011).

Different parts of Gloriosa superba L. have wide variety of uses especially in traditional system of medicine. Traditionally, the rural women prefer Gloriosa superba L. plant for gynecological disorders like abortion, menstrual trouble, conception disorders, sterility, delivery problems, etc rather than modern medicines. Tribes men of Patalkot apply the rhizome extract over the navel and vagina to induce labour and facilitate normal delivery. According to them, 250 to $500 \mathrm{mg}$ of the extract may lead to abortion if given to a lady with a pregnancy of $1-2$ months (Arati $e t$ al., 2011) Gloriosa superba L. also used in wounds, skin related problems, fever, inflammation, piles, blood disorders, uterine contractions (Haroon et al., 2008). The tuber of Gloriosa superba L. is used for the treatment of bruises and sprains, colic, chronic ulcers, haemorrhoids, cancer, impotence, nocturnal seminal emission, and leprosy and also for including labour pains and abortions (Kala, 2011).

Gloriosa superba L. show many pharmacological properties like anti-inflammatory (Jomy et al., 2009), Antimicrobial (Hemaiswarya, 2009), Antithrombotic/Anticoagulant potential (Kee et al., 2008), Anticancer activity (Reuter, 2010), Snake bite potential (Haroon, 2008), Hapatoprotactive activity (Mohandass, 2011), Antioxidant activity (Amudha and Shanthi, 2011) and Anthelmintic Activity (Pawar, 2010) etc. Roots are acrid, anthelmintic, antipyretic, bitter, digestive, expectorant, highly poisonous and promoting expulsion of the placenta. Root paste is effective against paralysis, rheumatism, snake bite and insect bites (Chitra and Rajamani, 2009).

\section{Materials And Methods:-}

\section{Sample collection and identification}

The study plant GloriosasuperbaL. (leaf, stem, flower) was collected near ArasanGanesanPolytechnique College, sivakasi in Tamilnadu. The collected plant sample was identified in the Department of Botany, The Standard Fireworks Rajaratinam College for women, Sivakasi in Tamilnadu. The sample was stored in shadow places for further analysis.

\section{Preparation Of Extracts}

The shadow dried Gloriosa superba L. samples (leaf, stem, flower) was powdered with the help of electronic blender. Twenty five gram of powdered plant material was taken in clean sterile Soxhlet apparatus and the 
extraction was done with $250 \mathrm{ml}$ of different solvents (low polar to high polar) like as hexane, butanol, ethanol, chloroform, water and acetone. Similarly, another 10 grams of GloriosasuperbaL.powder was extracted with 100ml of acetone. After extraction the extracts were dried in room temperature until extract reach into solid form. From the solid extract suitable concentrations were made using Dimethyl sulfo-oxide (DMSO) for further analysis.

\section{Seperation Of Active Compounds By Thin Layer Chromatography(Tlc)}

Gloriosa superba L. extracts were subjected to thin layer chromatography in order to separate the active compounds present in them. In the present study a modified form of the thin layer chromatography method was used and described by Farnsworth and Euler, 1962. Aqueous slurry of gel was prepared by $30 \mathrm{~g}$ of silica gel and 500mg of calcium sulphate in about $50 \mathrm{ml}$ of water. This was coated uniformly over the glass plate. The coated plate was activated at $100^{\circ} \mathrm{C}$ for 1 hour in hot air oven and allowed to cool. The extract was then spotted on the base of the plate. Then the plate was placed in the chamber, which is saturated with solvent composition Toluene - ethyl formate - formic acid $(5: 4: 1)$, and the chromatogram was developed until the solvent front was close to the top of the plate. A line was drawn across the plate. When the solvent reaches the line, the chromatogram was removed. The plate was dried in air. The Rf value was calculated by using the following formula.

$$
\mathrm{R}_{\mathrm{f}} \text { value }=\quad \begin{aligned}
& \text { Distance travelled by substance } \\
& -
\end{aligned}
$$

Identification of phytochemicals present in active acetone fraction of Gloriosa superba 1 . By gc-ms method The Gloriosa superba L.extracts after undergoing TLC and then separation of active fraction by column chromatography is subjected to GC-MS to identify the bio active constituents present in it. The GC-MS analysis is done in the IIT, Chennai, Tamilnadu, India. The analysis was performed using the equipment Thermo GC - Trace Ultra Ver: 5.0,Thermo MS DSQ II with the capillary column of DB 5 - MS capillary standard non - polar column which is $30 \mathrm{~m}$ long, $0.25 \mathrm{~mm}$ internal diameter with film thickness of $0.25 \mu \mathrm{m}$. $1 \mu \mathrm{l}$ of sample was taken for analysis. Helium was employed as carrier gas with flow of $1 \mathrm{ml}$ per minute. The oven temperature program was initially set as $70^{\circ} \mathrm{C}$ and raised upto $260^{\circ} \mathrm{C}$ at $6^{\circ} \mathrm{C}$ per minute. The run time of the sample is 37 minutes. The mass spectra of compounds in samples were obtained by electron ionization (EI) at $70 \mathrm{eV}$ and the detector operated in scan mode from 50 to 650 atomic mass units (amu). Identifications were based on the molecular structure, molecular mass and calculated fragmentations. Resolved spectra were identified for phytochemicals by using the standard mass spectral database of WILEY and NIST.

\section{Result and discussion:- \\ Identification of study plant material}

The collected plant sample was identified as GloriosasuperbaL.in the Department of Botany, The Standard Fireworks Rajaratnam College For Women, Sivakasi. In vitro antibacterial assay the efficacy ofGloriosasuperbaL.to inhibit the growth of pathogenic microbes showed the acetoneextract of the plants had broad spectrum of antibacterial potential. The antimicrobial activity, phytochemistry and anticancer activity (invitro and invivo) of Gloriosa superba L.leaves were analysed and recorded.

\section{Thin Layer Chromatography}

The crude extracts of Gloriosa superba L. leaves with various solvents were subjected to thin layer chromatography to separate the components present in it. The $\mathrm{Rf}$ value for each spots was calculated and presented in table 2.2. Hexane $0.17,0.22$ and water $0.12,0.26$ showed two spots, with respective Rf values. Butanol $0.07,0.11,0.34$ ethanol $0.06,0.18,0.30$ and chloroform $0.14,0.20,0.39$ showed three spots with respective Rf values. Acetone showed the maximum 4 spots with the Rf values of $0.03,0.05,0.11,0.12$. (Table 1.1).

Based on the antimicrobial assay, it was proved that the fraction 4 of acetone extract with Rf value 0.12 was found to be more active than other fractions. The separated fraction 4 of Gloriosa superba L. acetone extract was further analyzed by GCMS method for the identification of active components present in it. And this fraction is used for further analysis for its anticancer activity.

GC-MS analysis was performed to identify different compounds in the Gloriosa superba L. active acetone fraction. Thirty compounds were identified in GC-MS by library search tools. Thirty compounds were screened for bioactive 
compounds. Four compounds (Orphenadrine, Pheniramine, Chlorophenamine and Butanedioic acid, hydroxyl or Malic acid) were identified as bioactive compound and were listed in Table 1.2. Among them a single major peak is observed as Butanedioic acid, hydroxyl, also commonly known as Malic acid with RT value of 26.96 with peak area of $97.54 \%$. The molecular formula is $\mathrm{C}_{4} \mathrm{H}_{6} \mathrm{O}_{5}$ with molecular weight $134 \mathrm{Da}$. The chromatogram of GC-MS is shown in fig 1.1 and the library search result for structural prediction and identification is shown in fig 1.2.

Table 1.1:-Phytochemical analysis of GloriosasuperbaL.extracts using TLC method

\begin{tabular}{|r|r|r|r|}
\hline S.No & Extracts & Number of spots & \multicolumn{2}{|c|}{ Rf values } \\
\hline 1 & Hexane & 2 & $0.17,0.22$ \\
\hline 2 & Butanol & 4 & $0.07,0.11,0.34$ \\
\hline 3 & Ethanol & 4 & $0.06,0.17,0.30$ \\
\hline 4 & Chloroform & 3 & $0.14,0.20,0.39$ \\
\hline 5 & Aqueous & 2 & $0.12,0.26$ \\
\hline 6 & Acetone & 4 & $0.03,0.05,0.11,0.12$ \\
\hline
\end{tabular}

Table 2.3:-Bioactive compounds identified from the active acetone fraction of Gloriosasuperba L.extract by GCMS method

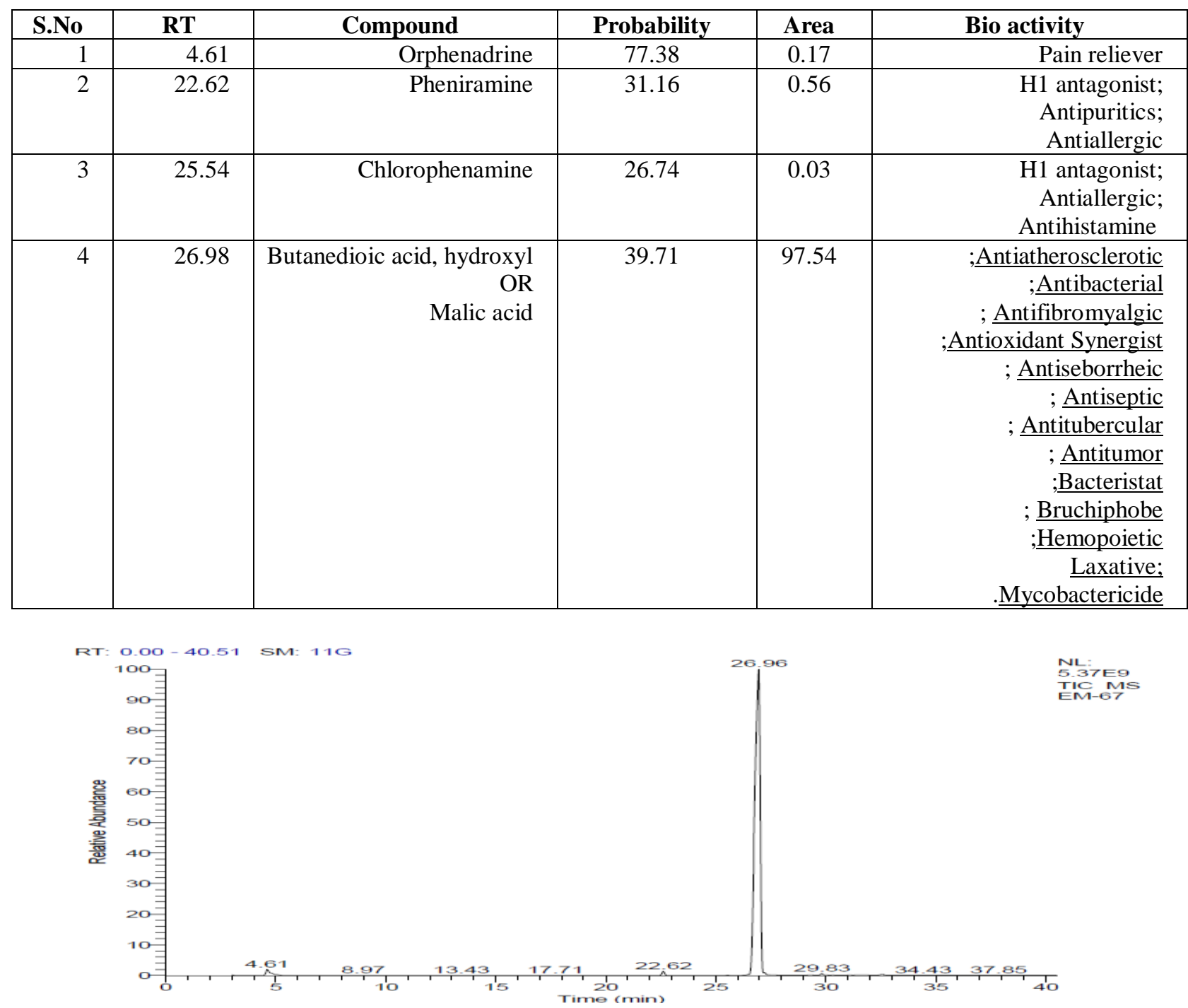

Fig 1.1:-GC-MS chromatogram of active acetone fraction of Gloriosa superba L.leaves extract 
Fig 1.2:-Library search graphics table for Malic acid identification
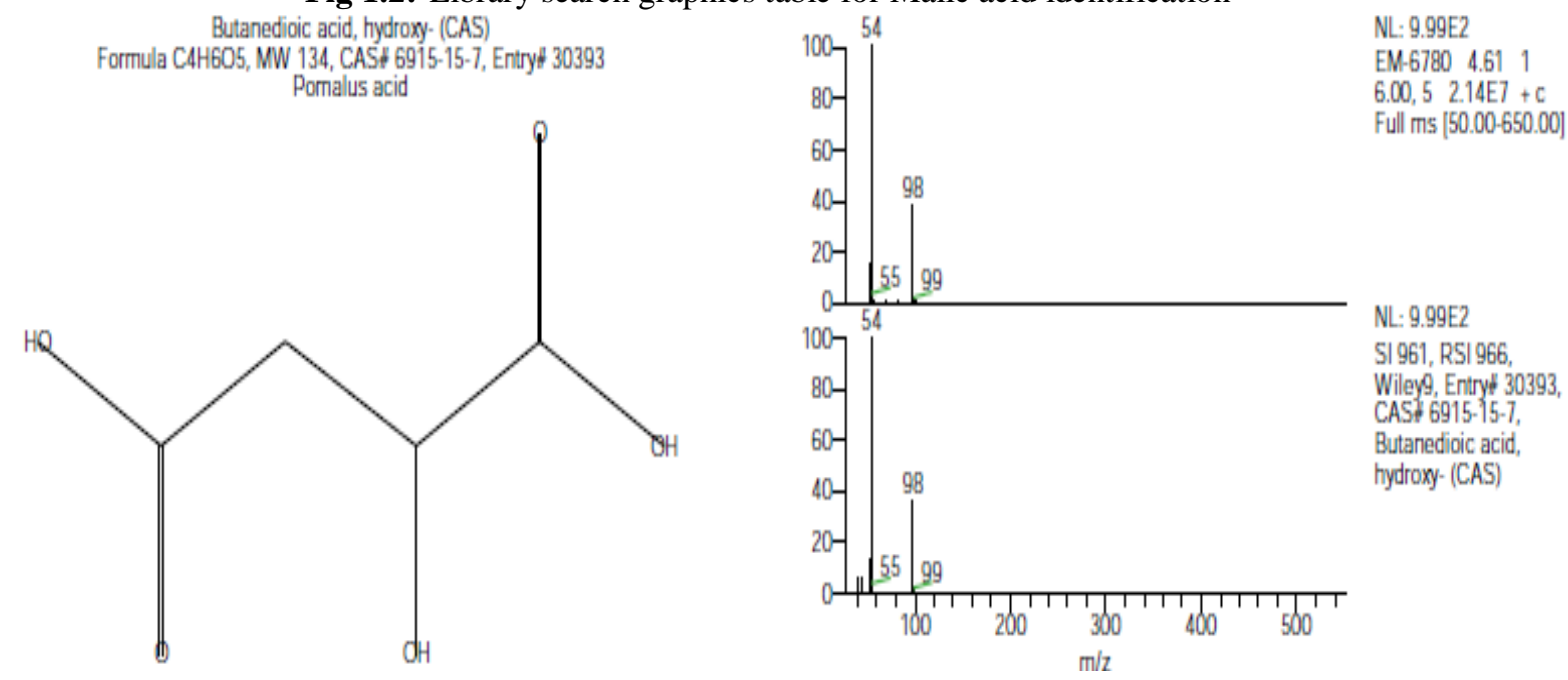

\section{Conclusion:-}

The crude extracts of Gloriosa superba L. leaves with various solvents were subjected to thin layer chromatography to separate the components present in it (Table1.1). Hexane showed two spots with the Rf values of $0.17,0.22$ and water $0.12,0.26$ also showed two spots with respective Rf values. Butanol 0.07, 0.11, 0.34, ethanol 0.06, 0.18, 0.30 and chloroform $0.14,0.20,0.39$ showed three spots with respective Rf values. Acetone showed the maximum 4 spots with the $\mathrm{Rf}$ values of $0.03,0.05,0.11,0.12$. Based on the antimicrobial assay, it was proved that the fraction 4 of acetone extract with Rf value 0.12 was found to be more active than other fractions. The separated fraction 4 of Gloriosa superba L. acetone extract was further analyzed by GC-MS method for the identification of active components present in it. Thirty bioactive compounds were identified and screened in GC-MS by library search tools. Among the thirty, four compounds (orphenadrine, pheniramine, chlorophenamine and butanedioic acid, hydroxyl or malic acid) were identified as bioactive compound. Among them a single major peak is observed as Butanedioic acid, hydroxyl, also commonly known as malic acid with RT value of 26.96 with peak area of $97.54 \%$ and this fraction is used further for anticancer studies.

Malic acid is the compound identified by GC-MS method (Table 1.2.). Similarly, presence of malic acid is reported in Gloriosa superba L.in Dr. Dukes Phytochemical and Ethnobotanical databases, and the database also reported that malic acid possess various bioactivities such as antiatherosclerotic, antibacterial, antifibromyalgia, antioxidant synergist, antiseborheic, antiseptic, antitubercular, antitumor, bacteriostat, hemopoietic, laxative, mycobactericide, pesticide and sialogue (Duke, 1985).Malic acid along with magnesium is taken as a drug to treat fibromyalgia. The other pharmacological activities of malic acid are still to be analyzed. In the present study in vitro analysis was done to discover the anticancer activity of malic acid.

\section{References:-}

1. Alam, M.T., Karim, M.M and Shakila, N. Khan. 2009. Antibacterial activity of different organic extracts of Achyranthes aspera and Cassia alata. Journal of Scientific Research. 1(2): 393-398.

2. Amudha, P. and Shanthi, P. 2011. Antioxidant activity of some rare medicinal plants. Journal of Environmental

3. Sciences. 11(2): 365-368.

4. Anwannil, H.G. and Atta, R. 2006. Trends in ethnopharmacology. Journal of Ethnopharmacology. 100: 43.

5. Arati, A., Malpani1, Urmila, M., Aswar, Shivk kushwaha, Zambare, G.N. and Bodhankar, S.L. 2011. Effect of the aqueous extract of Gloriosa superba Linn. (Langli). Roots on Reproductive System andCardiovascular Parameters in Female Rats. 10(2):169-176.

6. Asolkar, L.V., Kakkar, K.K. and Chakre, O.J. 1992. Second supplement to glossary of indian medicinal plants with active principles part I (A-K). (1965-81). CSIR, New Delhi. 18-20.

7. Baquar, S.R. 1995. The Role of Traditional Medicine in Rural Environment. Traditional Medicine in Africa. 2:141-142.

8. Bibitha, B., Jisha, V.K., Salitha, C.V., Mohan, S. and Valsa, A.K. 2002. Antibacterial activity of different plant extracts. Short Communication. Indian Journal of Microbiology. 42: 361-363. 
9. Bose, T.K., and L.P. Yadav. 1989. Commercial Flowers.Kolkata: Nayaprakash.

10. Chitra, R. and Rajamani, K. 2009. Perise performance and correlation studies for yield and its quality characters in

11. Glory lily Gloriosa superba (L). Academic Journal of Plant Science. 2:39-43.

12. Cragg, G.M. and Newman, D.J. 2001. Medicinal for the millennia. Ann.Ny Academic Science. 953: 3-25.

13. Duke, J.A. 1985. Medicinal plants of the Bible. Trado-Medic Books, Owerri, New York.

14. Farnsworth, N.R. and Euler, K.L. 1962. An alkaloid screening procedure utilizing thin-layer chromatography. Lloydia. 25(3): 186 - 193.

15. Haroon, K., Murad, A.K. and Iqbal, H. 2008. Enzyme inhibition activities of the extracts from rhizomes of Gloriosa superba Linn. (Colchicaceae). Journal of enzyme inhibition and medicinal chemistry. 22(6): 722-725.

16. Hemaiswarya, S., Raja, R., Anbazhagan, C. and Thiagarajan, V. 2009. Antimicrobial and mutagenic properties of the root tubers of Gloriosa superba Linn. Pakistan Journal of Botany. 41(1): 293-299.

17. Jana, S. and Shekhawat, G.S. 2011. Critical review on medicinally potent plant species: Gloriosa superba.L. Fitoterapia. 82(3):293-301.

18. Kala, C., Farooquee, N. and Dhar, U. 2004. Prioritization of medicinal plants on the basis of available knowledge, existing practices and use value status in Uttaranchal, India. Biodiversity and Conservation. 13(2): 453-469.

19. Kapoor,L.D. 2001. Tradicinal uses of medicinal plant In: Ayurvedic medicinal plant.CRC press, New Delhi.

20. Kavina, J., Gopi, R., and Panneerselvam, R. 2011. Gloriosa superba Linn. A Medicinally important plant. Drug Invention Today. 3(6): 69-71.

21. Kee, N.L.A., Mnonopi, N., Davids, H., Naude, R.J. and Frost, C.L. 2008. Antithrombotic / anticoagulant and anticancer activities of selected medicinal plants from South Africa. African Journal of Biotechnology. 7(3): 217-223.

22. Maghrani, M., Zeggwah, N., Michel, J. and Eddouks M. 2005. Antihypertensive effect of Lepidium sativum in spontaneously hypertensive rats. Journal of Ethnopharmocology. 102(1-2): 193-197.

23. Mahesh, B., and Sathish S. 2008. Antimicrobial activity of some important medicinal plant against plant and human pathogens. World Journal ofAgricultural Sciences. 4: 839-843.

24. Mohandass, S., Indhumathi, T. 2011. Hepatoprotective efficacy of Gloriosa superba Linn. against

25. paracetamol treated experimental rats-An in vivo study. Golden Research Thoughts. 1(4):

26. $1-4$.

27. Neuwinger, H. D. 1994. African ethnobotany poisons and drugs chemistry.Journal of Biological Chemistry. 24: 213-214.

28. Pawar, B.M., Wavhal, V.P., Pawar, N.D., Agarwal, M.R., Shinde, P.B., Kamble, H.V. 2010. Anthelmintic activity of antimicrobial activity of Eclipta alba and Morinda Citrifolia L. Middle-East. Journal of Science Research.6(5): 445-449.

29. Ravindra, A. and Mahendra, K. R. 2009. Review: Current advances in Gloriosa superba L. Biodiversitas.10(4): 210-214.

30. Reuter, S., Prasad, S., Phromnoi, K., Ravindran, J., Sung, B., Yadav, R.V., and Kannappan, R., 2010. Rhizomes of Gloriosa superba Linn. (Colchicaceae). Journal of enzyme inhibition and medicinal chemistry. 22(6): $722-$ 725 .

31. Samy, R.P., Thwin, M.M., Gopalakrishnakone, P. and Ignacimuthu, S. 2008. Ethnobotanical survey of folk plants for the treatment of snake bites in Southern part of Tamilnadu, India,a Venom and Toxin Research Programme. Journal of Ethnopharmacology. 115(2): 302-31.

32. Sivakumar, G. and Krishnamurthy, K.V. 2002. Gloriosa superba L. - a very useful medicinal plant. In: Recent Progress in Medicinal Plants. USA. 465-82.

33. Srivastava, J., Lambert, J. and Vietmeyer, N. 1996. Medicinal plants: An expanding role in development. World Bank Technical Paper. No.320.

34. Swarna priya, R., Doraipandian, A., Arumugam, T., and Radha, N.S. 1995. Floral biology of Gloriosa superba L. South Indian horticulture.43(1-2):40-41. 